\title{
The Virtual Field Trip: Investigating How to Optimize Immersive Virtual Learning in \\ Climate Change Education
}

Accepted in the British Journal of Educational Technology in the special issue Immersive Virtual Reality in Education on 3 June, 2020

Gustav B. Petersen ${ }^{1}$, Sara Klingenberg ${ }^{1}$, Richard E. Mayer ${ }^{2}$, \& Guido Makransky ${ }^{1}$

${ }^{1}$ University of Copenhagen, Department of Psychology

${ }^{2}$ University of California, Santa Barbara, Department of Psychological and Brain Sciences

Corresponding Author: Gustav B. Petersen, University of Copenhagen

Address: Øster Farimagsgade 2A, 1353 København K, gbp@ psy.ku.dk

- Gustav B. Petersen (gbp@psy.ku.dk) is a PhD student at the Department of Psychology at the University of Copenhagen. His research interests lie in the interplay between psychology and technology (e.g., instructional design of VR environments and, generally, learning with VR).

- Sara Klingenberg (sape@psy.ku.dk) is a student at the department of Psychology at the University of Copenhagen. Her research interests are related to how novel technologies can enhance learning experiences.

- Richard E. Mayer (mayer@psych.ucsb.edu) is Distinguished Professor of Psychology at the University of California, Santa Barbara. His research interests are in applying the science of learning to education, with current projects on multimedia learning, computer-supported learning, and computer games for learning 
- Guido Makransky (gm @ psy.ku.dk) is an Associate Professor at the Department of Psychology at the University of Copenhagen and the leader of the Virtual Learning Lab (virtuallearninglab.net) at the same institution. His current research focuses on understanding the mechanisms of learning in immersive learning environments.

This paper is not the copy of record and may not exactly replicate the final, authoritative version of the article. Please do not copy or cite without authors' permission. The final article will be available, upon publication, via its DOI: 10.1111/bjet.12991 


\begin{abstract}
Immersive Virtual Reality (IVR) is being used for educational virtual field trips (VFTs) involving scenarios that may be too difficult, dangerous, or expensive to experience in real life. We implemented an immersive VFT within the investigation phase of an inquiry-based learning (IBL) climate change intervention. Students investigated the consequences of climate change by virtually travelling to Greenland and exploring albedo and greenhouse effects first hand. A total of 102 7th and 8th grade students were randomly assigned to one of two instructional conditions: 1) narrated pre-training followed by IVR exploration or 2) the same narrated training material integrated within the IVR exploration. Students in both conditions showed significant increases in declarative knowledge, self-efficacy, interest, STEM intentions, outcome expectations, and intentions to change behavior from the pre- to post-assessment. However, there was a significant difference between conditions favoring the pre-training group on a transfer test consisting of an oral presentation to a fictitious UN panel. The findings suggest that educators can choose to present important prerequisite learning content before or during a VFT. However, adding pre-training may lead to better transfer test performance, presumably because it helps reduce cognitive load while learning in IVR.
\end{abstract}

Keywords: Immersive virtual reality, STEM education, middle school, head-mounted display, inquiry-based learning, transfer test performance 


\section{Practitioner notes}

What is already known about this topic?

- Immersive virtual reality (IVR) simulations lead to higher presence but may lead to less learning when the content is not designed based on the affordances of the technology. One explanation for this finding is that cognitive load may be higher in IVR.

- The pre-training principle (i.e., individuals learn more deeply from interactive multimodal learning environments when they receive pre-training on relevant prior knowledge) can be particularly effective in IVR-based learning compared to learning through a video.

- Evidence shows that instructional design principles such as segmentation and generative learning strategies such as summarization can improve learning in IVR simulations.

What this paper adds

- An investigation of the value of two different approaches to designing immersive virtual field trips (VFTs) within a real educational middle school context.

- Evidence that VFTs featuring IVR climate change simulations, in the context of inquirybased learning (IBL), can increase important variables such as declarative knowledge, interest in science, and intentions to take climate action in $7^{\text {th }}$ and $8^{\text {th }}$ grade students.

- Evidence that presenting important learning content before a VFT leads to higher transfer scores.

Implications for practice and/or policy

- Implementing an immersive VFT within the context of an IBL intervention provides students with relevant and engaging learning experiences and results in increased knowledge and interest in science. 
- In the design of instruction using VFTs, educators can choose to either present prerequisite learning content prior to a VFT or during a VFT. However, adding pre-training has an advantage in terms of higher transfer scores. 


\section{Introduction}

Consider learning about climate change by taking a virtual field trip (VFT) to the melting ice sheets of Greenland, through the technology of immersive virtual reality (IVR). The goal of this study is to examine the role of a VFT experience in changing beliefs and knowledge about climate change, and to examine how the instructional design of VFTs can promote transfer. IVR simulations are used in a variety of educational contexts to aid learning (e.g., laboratory safety training; Makransky et al., 2019a; spine surgery; Xin et al., 2019; immunology; Zhang et al., 2019). In an IVR environment, a head-mounted display (HMD) provides a computer-generated image of the virtual world that adapts in sync with the user's movements (Tarr et al., 2018). From an instructional point of view, the utility of IVR in modern education especially lies in its ability to support transfer (Dede et al., 2017). Transfer refers to applying knowledge learned in one situation to another context, and is an important goal of education (Prawat, 1989). By placing the learner in a virtual replica of the real-life situation for performance, IVR technology can foster the conditions for high levels of transfer. Besides advantages in terms of transfer, the potential of IVR environments include their ability to facilitate high fidelity experiences in realistic virtual environments containing scenarios that may be impossible, dangerous, or expensive to experience in real life (Bailenson, 2018). Thus, IVR may have the potential to aid instructors in their pursuit of exposing students to relevant learning experiences (see Meyer et al., 2019). However, research is needed to explore how best to exploit the potential of IVR for educational purposes.

\subsection{Virtual Field Trips}

One educationally-relevant use of IVR simulations is to send students on a VFT, i.e., a simulated expedition taken in a virtual environment without having to make a trip to the actual site (Woerner, 1999). In VFTs, students find themselves in a virtual environment with the autonomy to make observations on their own (Stainfield et al., 2000). VFTs can allow interaction, exploration, 
analysis, active learning, and testing of skills (Stainfield et al., 2000). Hence, VFTs are capable of assisting students in scientific inquiry.

The destination of travel in previous educational VFTs included the Arctic, Hershey's Factory, Le Louvre, and Mt. Everest (Stansbury, 2014), and topics have included animals (Han, 2019) as well as climate change (Markowitz et al., 2018), which is the topic in the present study. In this study, students participate in a VFT to Greenland in order to witness the melting ice sheet and explore the consequences of global warming. The challenges of climate change education include the invisibility of the phenomenon, the long time scale before Earth suffers the full consequences, the complexity of research, perceived lack of personal responsibility, and the perceived insignificance of individual contributions (Schreiner et al., 2005). A VFT experience could help combat some of these challenges currently facing climate change education, thereby promoting feeling of empowerment and desire for action in learners.

IVR enables VFTs to provide a high level of immersion. Immersion is defined as "the objective level of sensory fidelity" (Bowman \& McMahan, 2007, p. 38). High levels of immersion, in turn, may give rise to high levels of presence (Makransky \& Lilleholt, 2018). Presence can be defined as "the subjective experience of being in one place or environment, even when one is physically situated in another" (Witmer \& Singer, 1998, p. 225). As a result, students partaking in an immersive VFT may experience the trip as a viable substitute when the real experience is not easily accessible or affordable, as is the case of visiting the melting ice sheet of Greenland.

\subsection{Inquiry-Based Learning (IBL)}

Since VFTs allow for interaction, exploration, and analysis, they are especially compatible with instructional methods based on inquiry-based learning (IBL) where individual inquiry is essential. According to Mieg (2019), IBL is a didactic principle in which students learn by independently conducting their own research. A meta-analysis found that students who participated 
in inquiry learning (without guidance) tended to learn more than students who received traditional instruction, and that teacher-directed inquiry was even more effective (Furtak et al., 2012). IBL projects may vary in terms of time perspective (e.g., single session vs. semester-long) and degree of formality (e.g., based on student interest vs. designed by an educator), but learners are actively engaged in a knowledge-building process based on the generation and exploration of answerable questions (Chu et al., 2017). The act of inquiring into a topic and conducting one's own research (often with guidance from a teacher), may lead to the development of skills that are particularly in demand in the $21^{\text {st }}$ century. For instance, Gormally et al. (2009) found that IBL, through inquiry labs in the context of biology, significantly increased students' science literacy and science process skills. According to the Intergovernmental Panel on Climate Change, limiting global warming would require rapid and far-reaching transitions in energy, land, urban and infrastructure, and industrial systems (IPCC, 2018). Among other factors, such widespread transitions require students and a workforce with science and research related skills.

According to Pedaste et al. (2015), IBL can be divided into five phases: (1) Orientation, which introduces the learning topic (often including the introduction of a problem statement and main variables); (2) Conceptualization, which focuses on understanding concepts connected to the problem including generation of research questions and/or hypotheses to be investigated; (3) Investigation, where students carry out an investigation of the variables that make up the problem area including exploration, experimentation, experiment design, and data interpretation; (4) Conclusion, which involves addressing the original research questions and/or hypotheses; and (5) Discussion, where students communicate their findings and receive feedback as well as reflect on the entire process. Together, these inquiry phases constitute an inquiry cycle, designed to guide students in their IBL process and highlight key features of scientific thinking (Pedaste et al., 2015). 
In the present study, the immersive VFT was implemented within the investigation phase of an IBL climate change intervention, specifically to support exploration.

\subsection{Instructional Design of IVR}

An important consideration, besides the didactic approach, when working with immersive VFTs, is their instructional design. Instructional design deals with ways of creating multimedia presentations intended to promote learning (Mayer, 2014). For IVR simulations, the focus is on how the composition and design of lessons affect the learning experience in virtual environments.

Prior research indicates that immersion has mixed effects with regard to learning. For instance, Makransky and Lilleholt (2018) found that immersion caused learners to feel a sense of presence, which in turn increased their motivation and enjoyment in an IVR environment. On the other hand, Makransky et al. (2019b) found that presenting learning content via IVR was associated with less learning than when the same content was presented via a desktop computer. Similarly, Parong and Mayer (2018) found that students learned less from a lesson when it was presented via IVR than when it was presented as a slideshow on a desktop computer. These negative findings suggest that IVR simulations can be distracting for learning, thereby underscoring the significance of instructional design that minimizes cognitive load.

Studies investigating instructional design of IVR have pinpointed some techniques for improving learning in IVR. For example, asking students to summarize what they are learning after each segment of an IVR lesson in biology led to better learning outcomes than asking students to view a continuous IVR lesson without summarizing (Parong \& Mayer, 2018). In another study, gender-specific design of pedagogical agents played a critical role in improving learning outcomes in IVR learning environments (Makransky et al., 2018). IVR environments that, together with animation, present verbal material using speech rather than using on-screen text led to better learning outcomes (Moreno \& Mayer, 2002). Recently, the generative learning strategy of 
enactment has been found to be particularly beneficial for learning in IVR (Makransky et al., 2020). Finally, pre-training in key concepts led to better learning outcomes compared to no pre-training when learning with IVR (Meyer et al., 2019).

\subsection{The Current Study}

In the present study, middle school students take a virtual trip to Greenland to learn about the effects of global warming on the ice sheet. In particular, this study compares the effectiveness of providing pre-training in background information before the VFT versus presenting background information during the VFT. Presenting background information before the VFT is intended to reduce cognitive load during the virtual trip. There are three main objectives of this study. The first is to investigate how to optimize IVR learning in climate change education through implementing the abovementioned pre-training principle. Furthermore, the intervention is designed within a larger policy initiative from the Danish government that introduced a science, technology, engineering, and mathematics (STEM) education strategy in 2018 to increase interest and learning in STEM education and attract students to STEM education and careers (The Danish Ministry of Education, 2018). The background to this initiative is the recognition that science and technology are vital to Denmark's continued growth and welfare, and that dealing with global climate change and health threats, such as obesity epidemics and various cancers, demands a workforce with STEM skills (The Danish Ministry of Education, 2018). Therefore, the second objective is to investigate whether an inquiry-based science learning intervention using IVR as a VFT on the topic of climate change could increase interest and STEM intentions in middle school students. The third objective is to investigate whether the intervention could have an impact on students' climate-related behavioral change intentions. To achieve these objectives, we implemented an immersive VFT within the investigation phase of an IBL climate change intervention at a middle school, and examined the value of adding pre-training material prior to the VFT (pre-training condition) compared to listening 
to the same narrated training material integrated within the VFT (integrated condition). The outcome measures include changes in declarative knowledge, self-efficacy, interest, STEM intentions, outcome expectations, and intentions to change behavior, as well as performance on a transfer test.

\subsection{Theoretical Background and Predictions}

\subsubsection{Social Cognitive Career Theory}

Social Cognitive Career Theory is an empirically validated career theory, originally based on three models "designed to explain (a) how basic academic and career interests develop, (b) how educational and career choices are made, and (c) what factors affect academic and career success" (Lent et al., 2018, p. 17). The psychological variables of self-efficacy, interest, outcome expectations, and educational and career aspirations (also known as choice goals) are central to the theory. They are related in the following ways: high self-efficacy and positive outcome expectations with respect to a particular career-relevant activity leads to interest in that activity (or activity domain). Together with self-efficacy and outcome expectations, this career-related interest promotes particular educational and career aspirations (referred to as STEM intentions in this study; Lent et al., 2018). We conceptualize self-efficacy as an individual's perceived capabilities for learning or performing actions at designated levels (Schunk \& DiBenedetto, 2016). In this study, we focus on self-efficacy for climate change activities. Interest is the focused attention and affective reaction that is activated in the moment by certain environmental stimuli (Hidi \& Renninger, 2006). In this study, we focus on interest with respect to climate theory. Outcome expectations refers to beliefs about the consequences of certain actions (Lent et al., 2008). In this study, we measure outcome expectations as the perceived social possibilities associated with an environmental career. Finally, STEM intentions is an individual's plan to pursue an education and a career within the 
natural sciences. These variables are addressed in the present study due to their relevance for illuminating how an educational activity can lead to increased interest and STEM intentions.

Empirical research on the use of VR for learning suggests that it can effectively influence students' self-efficacy (Makransky \& Petersen, 2019) and interest (Parong \& Mayer, 2018). This is consistent with the finding that interest can be triggered by novelty (Wade, 1992), which often is the case for using a new technology like VR in education. Furthermore, the IBL climate change intervention provides the students with hands-on experiences (regarding the scientific inquiry related to climate research) as well as feedback, which are essential components in developing selfefficacy (Schunk \& Pajares, 2002). Therefore, we make the following predictions:

We expect students in both conditions to show significant improvements in ratings of selfefficacy from pre- to post-assessment (Hypothesis 1).

We expect students in both conditions to show significant improvements in ratings of interest from pre- to post-assessment (Hypothesis 2).

It was not possible to identify prior research concerning the effect of VFTs on students' outcome expectations. However, it is likely that the high levels of presence experienced in IVR, in addition to the IBL-activities, provided an appealing and realistic insight into life as a climatescientist. This led to the third hypothesis:

We expect students in both conditions to show significant improvements in ratings of outcome expectations from pre- to post-assessment (Hypothesis 3).

Theoretically, career-related interests, together with self-efficacy and outcome expectations, promote particular educational and career intentions. Since the intervention is expected to have a positive effect on the participants' interest, self-efficacy, and outcome expectations regarding the academic area of climate change, we predict an increase in their STEM intentions as well: 
We expect students in both conditions to show significant improvements in ratings of STEM intentions from pre- to post-assessment (Hypothesis 4).

\subsubsection{Behavioral change intentions}

In this study, behavioral change intentions account for an individual's intentions to be and act more climate consciously. A recent meta-analysis on the factors that motivate adaptation behaviors related to climate change (i.e., adjustment so that negative impacts of climate change can be reduced), found that risk perception, belief in the reality of climate change, negative affect, and perceived responsibility were predictors of adaptive behavior (van Valkengoed \& Steg, 2019). These are factors that the intervention was designed to increase. This is consistent with the Protective Action Decision Model (PADM), which explains people's protective action decisions in response to perceived environmental hazards. According to the PADM, environmental cues, social cues, and socially transmitted warnings are central elements in protective action decision making (Lindell \& Perry, 2012). It can be argued that such cues were part of the VFT to Greenland. Therefore:

We expect students in both conditions to show significant improvements on ratings of intentions to change behavior from pre-to post-assessment (Hypothesis 5).

\subsubsection{Cognitive-Affective Theory of Learning with Media}

The Cognitive-Affective Theory of Learning with Media is a theory that describes how people learn with media such as virtual reality. It is based on the following assumptions: (1) People have distinct channels for processing different information modalities, (2) A limited amount of information can be processed at a time within each of these channels, (3) Meaningful learning happens when one spends conscious effort in cognitive processes, like integrating information with prior knowledge, (4) Long-term memory consists of memory of past experiences and general domain knowledge, (5) Motivational factors mediate learning by affecting cognitive engagement, 
(6) Metacognitive factors facilitate learning by regulating cognitive processing and affect, and (7) Differences in prior knowledge and abilities can affect how much is learned with particular media (Moreno \& Mayer, 2007). The theory proposes instructional design principles intended to optimize learning by reducing the degree of unnecessary processing so that the learner's limited cognitive resources can be used to engage in necessary processing of the given material (Moreno \& Mayer, 2007). The pre-training principle constitutes such a design principle and states that individuals learn more deeply from interactive multimodal learning environments when they receive pre-training that triggers or provides relevant prior knowledge before the main lesson (Moreno \& Mayer, 2007). In this way, the learner has prior knowledge they can use to process the message with less cognitive effort, leading to better understanding (Mayer \& Pilegard, 2014). Therefore:

We expect students in the pre-training condition to improve more than students in the integrated condition on a measure of declarative knowledge (Hypothesis 6).

We expect students in the pre-training condition to score higher than students in the integrated condition on a transfer test consisting of an oral presentation (Hypothesis 7).

\section{Method}

\subsection{Participants and Procedure}

The sample consisted of $1027^{\text {th }}(\mathrm{N}=26)$ and $8^{\text {th }}(\mathrm{N}=76)$ grade students $(36$ boys and 66 girls). The experiment was conducted in the context of an IBL workshop on climate change held at a technology lab for schools in Denmark. Figure 1 shows an overview of the different elements of the workshop and their connections to the various phases of IBL. The technology lab is part of a municipal educational initiative where students are able to use modern technology as part of their education. Therefore, teachers had signed up their students as part of a standard educational activity. The workshop was conducted six times with up to 24 students each time, and each session was identical and consisted of the following procedure: 
First, participants were given a pre-assessment. Following this, they were randomly assigned to (1) the pre-training group, which received narrated pre-training followed by IVR exploration $(\mathrm{N}=50)$ or $(2)$ the integrated group, which received the same narrated training material integrated within the IVR exploration ( $\mathrm{N}=52$; see top panel of Figure 2). Before starting the IVR sessions, all students were instructed in the scientific method by their respective teachers, who were biology or natural geography teachers. Furthermore, all participants engaged in a plenary discussion, which introduced the issue that not everyone believes in climate change, and that evidence would be necessary to convince the skeptics. This part of the workshop corresponded to the orientation phase in IBL, as the learning topic (climate change) was introduced along with a problem statement and the central methodological variables. After this, the integrated group started the VFT, while the pre-training group listened to the narration in a separate room, and then started the non-narrated version of the VFT. This part of the workshop drew upon elements of the orientation and investigation phases in IBL, as the students received information about climate theory and engaged in exploration of its real-life manifestations (at the same time or separately, depending on the condition). After completing the VFT, the students in each condition were required to work together in groups of three or four. Based on their experience in the IVR session, the groups had to come up with specific hypotheses about the causes of climate change and suggest possible experimental designs that could test them. This part of the workshop drew upon elements of the conceptualization and investigation phases in IBL, as the students generated research questions and hypotheses, and came up with an experimental design. Afterwards, each group had to present their experimental design to a fictitious UN panel (consisting of members of the research team). The workshop concluded with each student completing a post-assessment (a full list of items and the source of the scales is included in Appendix A). The final part of the workshop 
corresponded to the conclusion and discussion phases in IBL, as the participants made conclusions about their observations, communicated their research, and received feedback.

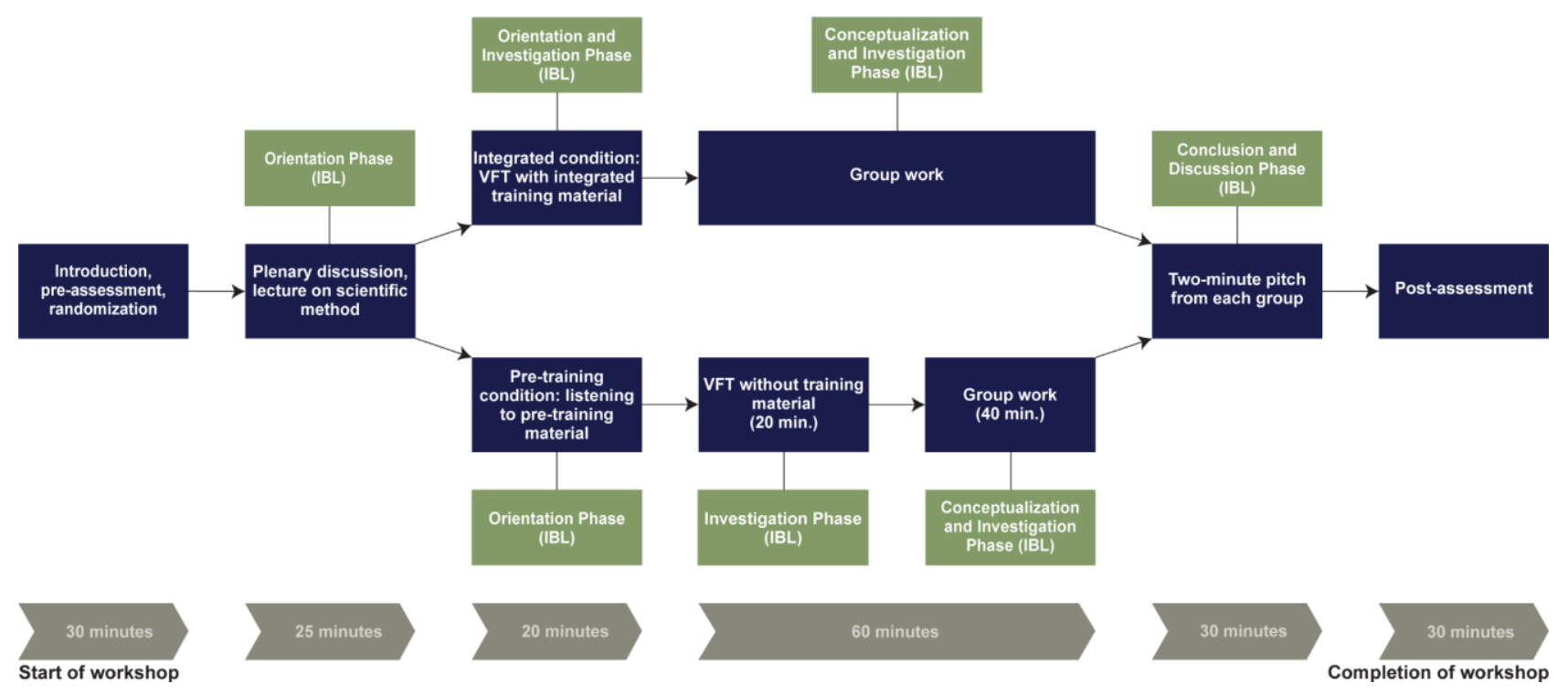

Figure 1. Overview of the workshop and its connections to the phases of IBL.

As illustrated in Figure 1, one of the initial steps in the workshop was a plenary discussion and a teacher-lead lecture on the scientific method. First, teachers read a fictitious article out loud for the students. In this article, the author, a made-up character named Dr. Patrick Morgan, argues that climate change is a myth and that people should not believe scientists who say otherwise. However, it appears from the article that Dr. Morgan is funded by the oil industry. Thus, the article sets the stage for a plenary discussion about the author, who can be considered marked by special interests which could affect his intentions, and secondly, about scientific argumentation in general. Accordingly, the students were introduced to the issue that not everyone believes in climate change, and that sound, scientific proof would be necessary to convince the skeptics. After the plenary discussion of the article, the teachers started their lecture on scientific method. This was based on the following six elements: observation, research, question, hypothesis, prediction, and experiment, which provided the basis for the students' group work with regard to developing experimental designs. 


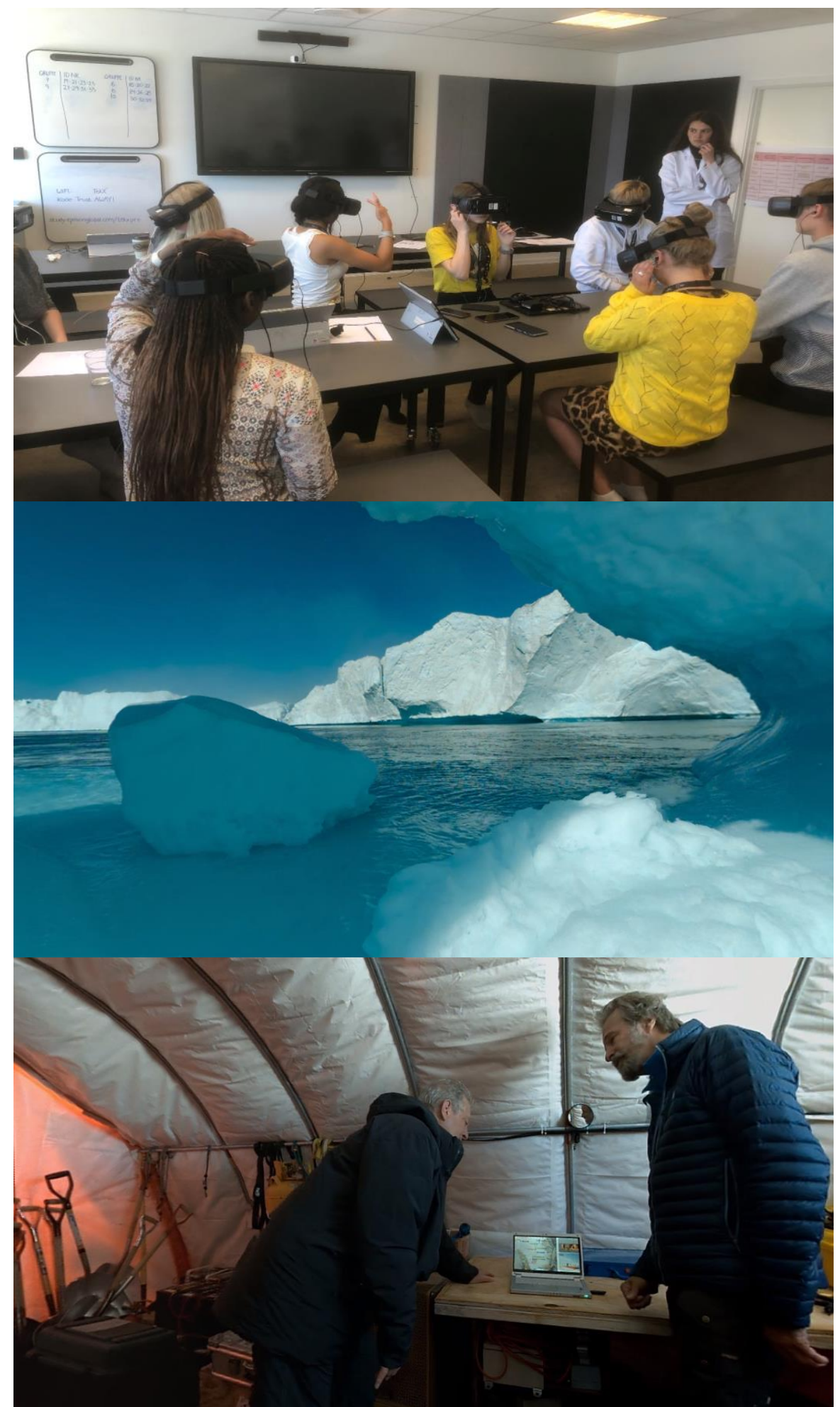

Figure 2. Picture from the intervention (top) and screenshots from the VFT (mid and bottom). 


\subsection{Materials and Apparatus}

The materials consisted of an immersive VFT to Greenland, exercise prompts, as well as survey and test items. The immersive VFT was a documentary called This is Climate Change: Melting Ice (Dennis \& Strauss, 2018): a $360^{\circ}$ non-interactive IVR video concerning the melting Greenland ice sheet, in which the viewer follows former vice president Al Gore on an exploration into different areas in Greenland affected by climate change (see Figure 2 for screenshots). It was presented via Samsung S7 or S8 phones with headphones and displayed through Samsung Gear VR HMDs. Using high-quality audio recording equipment (yeti from Blue), the authors recorded a narration about the greenhouse effect, ice-albedo feedback, and ocean acidification, intended to supplement the VFT with additional learning content. These concepts laid a foundation for the students' later group work and made the VFT more relevant as a learning experience, as the video in itself does not include conceptual knowledge and theory about climate change. With permission from the creators of the documentary, the original version of the VFT was merged with the narration and used in the integrated condition. The same narration was used in the pre-training condition, in which the participants listened to it before beginning the original, unedited version of the VFT.

Inspired by what they had learned, students worked together in groups to design an experiment that could test their hypotheses about the causes of climate change. This took approximately one hour for the integrated groups and about forty minutes for the pre-training groups. The group work followed the same structure for all groups as they had to fill out an exercise sheet that could be used as preparation for their presentations at the end of the day (see Appendix B for a list of the questions included). Teachers were available to respond to questions and provide assistance. Lastly, all groups presented their work to a hypothetical UN climate change panel, made up of researchers, in a two-minute pitch in front of the rest of the class. 
The pre-assessment measured demographic characteristics (age, grade, and gender) and initial levels of self-efficacy, interest, STEM intentions, behavioral change intentions, outcome expectations, and knowledge. Except demographic characteristics, the same variables were measured again in the post-assessment. Self-efficacy was assessed with six items adapted from Makransky et al. (2016) and had a Cronbach's alpha of 0.79 in the pre-assessment and 0.88 in the post-assessment. Interest was assessed with four items adapted from Thisgaard and Makransky (2017; alpha $=0.85$ in the pre-assessment; and 0.93 in the post-assessment). STEM intentions was assessed with four questions adapted from Thisgaard and Makransky (2017; alpha $=0.76$ in the preassessment; and 0.84 in the post-assessment). Behavioral change intentions were assessed with three items (alpha $=0.83$ in the pre-assessment; and 0.79 in the post-assessment). Outcome expectations were assessed with three items adapted from Makransky et al. (2019c; alpha $=0.73$ in the pre-assessment; and 0.79 in the post-assessment). The items in the self-efficacy, interest, STEM intentions, behavioral change intentions, and outcome expectations scales used a five-point Likert scale ranging from (1) strongly disagree to (5) strongly agree.

The knowledge test was based on seven multiple choice questions and four polytomous questions. The maximum possible score in the knowledge test was 27 (Cronbach's alpha $=0.70$ in the post-assessment) as two response options were deleted because they did not correlate positively with the other items (items $6 \mathrm{~b}$ and $8 \mathrm{a}$ in Appendix A). The transfer test consisted of the students' performance scores from the presentation to the fictitious UN Panel and were scored independently by two raters on three criteria including: 1) general assessment of the quality of the scientific method, 2) academic understanding, and 3) hypothesis. The two independent ratings had a correlation of 0.84 so the sum score was used. Each criterion was scored on a scale from 1 (incomplete) to 5 (excellent).

\section{Results}


Prior to investigating the hypotheses, we examined whether the groups differed with regard to demographic characteristics. An independent-samples t-test indicated that there were no significant age differences between participants in the pre-training condition $(M=14.18, S D=0.75)$ and in the integrated condition $(M=14.44, S D=0.75) t_{(100)}=1.77, p=.080$. A Chi-square test for independence indicated no significant gender differences between participants in the pre-training condition and in the integrated condition, $\mathrm{X}^{2}(1, n=102)=.02, p=.884$. We conclude that the groups were equivalent on basic characteristics. Table 1 shows the means and SDs of the two groups on pre-assessment and post-assessment scores for six measures and post-assessment score for one measure.

\section{Hypothesis 1 through 5: Students in both conditions will show significant improvements in self-efficacy, interest, outcome expectations, STEM intentions, and behavior change intentions from pre- to post-assessment.}

Hypothesis 1 through 5 were investigated with a two-group (pre-training / integrated) by two-time points (pre- / post-assessment) mixed between-within subjects ANOVA. The top row of Table 1 shows that there was a significant main effect for time with regard to self-efficacy across groups, $F_{(1,100)}=125.98, p<.0005, \eta_{p}^{2}=.56$. There was not a significant interaction between condition and time, $F_{(1,100)}=2.40, p=.125, \eta_{p}{ }^{2}=.02$. Thus, Hypothesis 1 was supported.

The second row of Table 1 shows that there was a significant main effect for time with regard to interest in climate theory across groups, $F_{(1,100)}=32.84, p<.0005, \eta_{p}{ }^{2}=.25$. There was not a significant interaction between condition and time, $F_{(1,100)}=1.68, p=.198, \eta_{p}{ }^{2}=.02$. Thus, Hypothesis 2 was supported.

The results on the third row of Table 1 indicated that there was a significant main effect for time with regard to outcome expectations across groups, $F_{(1,100)}=5.14, p=.026, \eta_{p}{ }^{2}=.05$. There 
was not a significant interaction between condition and time, $F_{(1,100)}=0.20, p=.653, \eta_{p}{ }^{2}=.00$. Thus, Hypothesis 3 was supported.

The results on the fourth row of Table 1 indicated that there was a significant main effect for time with regard to STEM intentions across groups, $F_{(1,100)}=16.20, p<.0005, \eta_{p}{ }^{2}=.14$. There was not a significant interaction between condition and time, $F_{(1,100)}=0.10, p=.752, \eta_{p}{ }^{2}=.00$. Thus, Hypothesis 4 was supported.

The results on the fifth row of Table 1 indicated that there was a significant main effect for time with regard to behavior change intentions across groups, $F_{(1,100)}=6.35, p=.013, \eta_{p}{ }^{2}=.06$. There was not a significant interaction between condition and time, $F_{(1,100)}=0.28, p=.600, \eta_{p}{ }^{2}=$ .00. Thus, Hypothesis 5 was supported. In conclusion, the results supported Hypothesis 1 through 5 in this study.

\section{Hypothesis 6: Students in the pre-training condition will improve more than students in the integrated condition on a measure of declarative knowledge.}

Hypothesis 6 was investigated with a two-group (pre-training / integrated) by two time points (pre- / post-assessment) mixed between-within subjects ANOVA. The results on the sixth row of Table 1 indicated that there was a significant main effect for time with regard to declarative knowledge across groups, $F_{(1,100)}=39.49, p<.0005, \eta_{p}^{2}=.28$. There was not a significant interaction between condition and time, $F_{(1,100)}=0.05, p=.831, \eta_{p}{ }^{2}=.00$. Thus, both groups had significantly higher declarative knowledge scores, but the differences between the groups was not significant. Therefore, Hypothesis 6 was not supported.

\section{Hypothesis 7: Students in the pre-training condition will score higher on a transfer test than students in the integrated condition.}

Hypothesis 7 was investigated with an independent-samples t-test. The results on the final row of Table 1 indicated that there was a significant difference in transfer scores between the 
groups, favoring the pre-training condition $(M=25.52, S D=5.03)$ over the integrated condition $(M$ $\left.=23.02, S D=5.71) ; t_{(99.26)}=2.35, p=.021, \mathrm{~d}=0.46\right)$. Thus, Hypothesis 7 was supported.

Table 1. Means and standard deviations for the two conditions on the seven outcome variables in the study.

\begin{tabular}{|c|c|c|c|c|c|c|c|}
\hline & & \multicolumn{2}{|c|}{ Pre-assessment } & \multicolumn{2}{|c|}{ Post-assessment } & \multicolumn{2}{|c|}{ Significance } \\
\hline & & Integrated & $\begin{array}{c}\text { Pre- } \\
\text { training }\end{array}$ & Integrated & $\begin{array}{c}\text { Pre- } \\
\text { training }\end{array}$ & Time & $\begin{array}{l}\text { Interaction } \\
\text { /Condition } \\
\end{array}$ \\
\hline H1 & Self-Efficacy & $3.10(0.63)$ & $\begin{array}{c}3.30 \\
(0.68)\end{array}$ & $4.03(0.70)$ & $\begin{array}{c}4.00 \\
(0.67)\end{array}$ & $p<.0005$ & $p=.125$ \\
\hline $\mathrm{H} 2$ & Interest & $3.42(0.92)$ & $\begin{array}{c}3.72 \\
(0.82)\end{array}$ & $3.96(0.96)$ & $\begin{array}{c}4.06 \\
(0.87)\end{array}$ & $p<.0005$ & $p=.198$ \\
\hline $\mathrm{H} 3$ & $\begin{array}{c}\text { Outcome } \\
\text { Expectations }\end{array}$ & $3.44(0.81)$ & $\begin{array}{c}3.67 \\
(0.75)\end{array}$ & $3.62(0.84)$ & $\begin{array}{c}3.79 \\
(0.79)\end{array}$ & $p=.026$ & $p=.653$ \\
\hline $\mathrm{H} 4$ & $\begin{array}{c}\text { STEM } \\
\text { Intentions }\end{array}$ & $2.43(0.83)$ & $\begin{array}{c}2.72 \\
(0.90)\end{array}$ & $2.70(1.01)$ & $\begin{array}{c}2.95 \\
(0.90)\end{array}$ & $p<.0005$ & $p=.752$ \\
\hline H5 & $\begin{array}{l}\text { Behavior } \\
\text { Change } \\
\text { Intentions }\end{array}$ & $3.63(0.88)$ & $\begin{array}{c}3.70 \\
(1.00)\end{array}$ & $3.81(0.80)$ & $\begin{array}{c}3.81 \\
(0.95)\end{array}$ & $p=.013$ & $p=.600$ \\
\hline H6 & Knowledge & $14.27(2.86)$ & $\begin{array}{l}14.52 \\
(3.09)\end{array}$ & $16.54(4.60)$ & $\begin{array}{l}16.64 \\
(4.06)\end{array}$ & $p<.0005$ & $p=.831$ \\
\hline $\mathrm{H} 7$ & Transfer & NA & NA & $23.02(5.71)$ & $\begin{array}{r}25.52 \\
(5.03)\end{array}$ & NA & $p=.021$ \\
\hline
\end{tabular}

For H1-H6, p-values from Mixed Between-Within Subjects ANOVAs (time and interaction) are presented. For H7, the p-value is from the Independent Samples T-Test (condition).

\section{Discussion}

\subsection{Empirical Contributions}

The results of this study indicated that the only learning outcome that benefited more by introducing pre-training to an IBL climate change intervention was transfer of knowledge. This can be taken to indicate that both approaches to the instructional design of VR (i.e. integrating and separating instructional material) may be beneficial for a number of important learning outcomes when placed in an IBL context, but also that adding pre-training may lead to better transfer test performance, presumably because it helps reduce cognitive load while learning in IVR. This is a major empirical contribution of this study and supports previous research by Meyer and colleagues 
(2019) who report a Cohen's $d$ of 0.62 for pre-training in IVR, which is slightly higher than the effect size of 0.46 identified in this study.

Consequently, this study seems to corroborate previous findings with regard to using IVR in education. Namely, that it can help improve learners' self-efficacy (Makransky et al., 2019a), interest (Parong \& Mayer, 2018), and knowledge (Queiroz et al., 2018) with respect to specific topics - in this case, climate change. The increase in STEM intentions and outcome expectations of an environmental career are also encouraging, especially since the demand for employees with a background in, and a skillset related to STEM fields continues to increase (Carnevale et al., 2011). From a climate change perspective, the fact that the students across conditions showed significant improvements in behavioral change intentions is highly promising, and highlights the potential of IVR, in connection with relevant educational activities, to decrease psychological distance and thereby increase climate action (Bailenson, 2018). It is, however, important to highlight that the individual contribution of IVR to these results cannot be isolated as it appeared as part of an IBL intervention on climate change which also featured other learning activities.

\subsection{Theoretical Contributions}

Social Cognitive Career Theory explains the underlying mechanisms of how students make educational and career choices: self-efficacy, positive outcome expectations, and interest with respect to a specific activity domain lead to intentions to pursue an education and a career related to that domain, which ultimately increases the likelihood of the student acting on these intentions (e.g., seeking admission into higher education). In this study, the IBL climate change intervention featuring a VFT led to significant increases in self-efficacy, outcome expectations, interest, and STEM intentions across conditions. As such, the results fit with the Social Cognitive Career Theory's theoretical framework, and illustrate how a learning intervention containing IVR may lead 
to increased (short-term) STEM intentions, possibly because of increased self-efficacy, outcome expectations, and interest regarding the academic area of climate change.

Several instructional design principles can be derived from the Cognitive Affective Theory of Learning with Media. Many of these have been validated with non-interactive learning environments; however, the effect of introducing design principles into highly interactive learning environments, such as IVR, still needs to be researched more extensively. The findings from this study indicate that the pre-training principle may contribute to optimizing transfer of immersive virtual learning in climate change education.

There are no specific guidelines on what constitutes appropriate pre-training material, besides that it should provide learners with relevant prior knowledge. However, most previous studies have introduced pre-training materials that give the learner a brief overview of central concepts associated with a learning topic prior to administering a self-contained lesson (e.g., Mayer et al., 2002; Meyer et al., 2019). The pre-training material used in present study did not just constitute a brief overview of climate theory in shape of, e.g., a drawing, but an extensive explanation of the greenhouse effect, ice-albedo feedback, and ocean acidification. In addition, the VFT was not self-contained, per se, as the non-narrated version did not include knowledge about these theoretical concepts. Therefore, students in the integrated condition most likely experienced higher cognitive load during the VFT, whereas students in the pre-training condition could focus on exploring and drawing parallels between what they had heard and what they were seeing. Yet, the groups did not differ with regard to declarative knowledge gain, as predicted by the theory.

\subsection{Practical Implications}

The IBL climate change intervention can be used as a framework for how educators could use IVR as part of inquiry-based workshops or courses. As shown in Figure 1, the inquiry cycles were slightly different for each condition. In the integrated condition, IVR was used to support 
orientation and investigation at once, as the students went on the VFT while receiving knowledge about climate change at the same time. In the pre-training condition, IVR was used exclusively to support investigation, as the students listened to the pre-training material before engaging in the VFT. The findings suggest that VFTs can be a useful alternative to going on an actual field trip in cases where it would be difficult to do so (e.g., going to Greenland). Educators can choose to use VFTs either as a tool for investigation following orientation (pre-training) or as a tool for joint investigation and orientation (integrated), as both uses led to increases in important learning outcomes. However, choosing the pre-training variation may leader to better transfer performance.

\subsection{Limitations}

One of this study's limitations was that we could not isolate the exact effect of IVR on the learning outcomes, as the students took the post-assessment at the end of the workshop. However, the aim was to investigate the efficacy of using a VFT as part of an IBL activity, as well as how the VFT should be designed. In that sense, the IBL climate change intervention reflected an ecologically valid learning activity utilizing IVR. Also, interpretation of the pre- to post-assessment gains must be interpreted in light of the fact that there was no control group. Thus, we cannot exclude the possibility that another instructional technology could have produced similar findings. For instance, Varma and Linn (2012) investigated the effect of a web-based IBL environment concerning global warming on students' understanding of climate theory. They reported significant improvement on individual knowledge items with Cohen's d effect sizes ranging from 0.19 to 0.69 (Varma \& Linn, 2012). By comparison, the main effect with regard to declarative knowledge in this study had an effect size of $.28\left(\eta_{p}{ }^{2}\right)$, which corresponds to a large effect (Richardson, 2011). It would be useful to conduct a similar study on immersive VFTs in the context of IBL with a control group that receives the same treatment delivered through another instructional technology such as computer or video. 
Furthermore, no behavioral data from the VFT was collected. This could potentially have added value to the findings as eye-tracking, for instance, can be used as an indicator of where, and how long, the students looked at the different objects in the virtual environment, and pupil dilation can be an indicator of cognitive load (Pomplun \& Sunkara, 2003). Future research should investigate such behavioral measures as potential moderators of learning in IVR.

Lastly, a limitation is that we did not measure actual behavior change but only intentions to change behavior. It would have been interesting to have a follow-up test that measured if the students had actually implemented behavior changes in their daily lives. This could for instance involve measures of how much they recycled, bought second-hand clothes, etc. Similarly, a delayed assessment of the same variables measured in the pre- and post-assessments could have shown whether the observed increase in learning outcomes persisted.

\section{Conclusion}

Implementing an immersive VFT within the investigation phase of an IBL climate change intervention had a positive effect on students' declarative knowledge, self-efficacy, interest, STEM intentions, outcome expectations, and intentions to change behavior. Moreover, listening to pretraining material before the VFT led to better transfer test performance compared to integrating it in the VFT, presumably because it helped reduce cognitive load. Instructors can use the intervention described in this paper as a framework for how to conduct IBL activities including VFTs.

Acknowledgements: We would like to thank all the teachers and students who participated in the study. We would also like to thank Bjarke Lindsø Andersen and Simon Ryberg Madsen.

Statements on open data, ethics, and conflict of interest: No conflicts of interest to declare. Data available upon request. This study was approved by the ethics committee at the Department of Psychology, University of Copenhagen. 


\section{References}

Bailenson, J. (2018). How to build good VR content. In J. Bailenson (Ed.), Experience on demand: What virtual reality is, how it works, and what it can do (pp. 247-260). Norton \& Company.

Bowman, D. A., \& McMahan, R. P. (2007). Virtual reality: How much immersion is enough? Computer, 40(7), 36-43. https://doi.org/10.1109/MC.2007.257

Carnevale, A. P., Smith, N., \& Melton, M. (2011). STEM: Science technology engineering mathematics. Georgetown University Center on Education and the Workforce.

Chu, S. K. W., Reynolds, R. B., Tavares, N. J., Notari, M., \& Lee, C. W. Y. (2017). Introduction. In S. K. W. Chu, R. B. Reynolds, N. J. Tavares, M. Notari, \& C. W. Y. Lee (Eds.), 21 st century skills development through inquiry-based learning: From theory to practice (pp. 3-16). Springer Singapore. https://doi.org/10.1007/978-981-10-2481-8_1

Dede, C., J., Jacobson, J., \& Richards, J. (2017). Introduction: Virtual, augmented, and mixed realities in education. In D. Liu, C. Dede, R. Huang, \& J. Richards (Eds.), Virtual, augmented, and mixed realities in education (pp. 1-16). Springer Nature.

Dennis, D., \& Strauss, E. (2018). This is climate change: Melting ice. https://www.with.in/watch/this-is-climate-change-melting-ice

Furtak, E. M., Seidel, T., Iverson, H., \& Briggs, D. C. (2012). Experimental and quasi-experimental studies of inquiry-based science teaching: A meta-analysis. Review of Educational Research, 82(3), 300-329. https://doi.org/10.3102/0034654312457206

Gormally, C., Brickman, P., Hallar, B., \& Armstrong, N. (2009). Effects of inquiry-based learning on students' science literacy skills and confidence. International Journal for the Scholarship of Teaching and Learning, 3(2). https://doi.org/10.20429/ijsotl.2009.030216

Han, I. (2019). Immersive virtual field trips in education: A mixed-methods study on elementary students' presence and perceived learning. British Journal of Educational Technology, 51(2), 
1-16. https://doi.org/10.1111/bjet.12842

Hidi, S., \& Renninger, K. A. (2006). The four-phase model of interest development. Educational Psychologist, 41(2), 111-127. https://doi.org/10.1207/s15326985ep4102_4

IPCC. (2018). Summary for policymakers. In V. Masson-Delmotte, P. Zhai, H.-O. Pörtner, D. C. Roberts, J. Skea, P. R. Shukla, A. Pirani, W. Moufouma-Okia, C. Péan, R. Pidcock, S. Connors, J. B. R. Matthews, Y. Chen, X. Zhou, M. Gomis, E. Lonnoy, T. Maycock, M. Tignor, \& T. Waterfield (Eds.), Global warming of $1.5^{\circ} \mathrm{C}$ : An IPCC special report on the impacts of global warming of $1.5^{\circ} \mathrm{C}$ above pre-industrial levels and related global greenhouse gas emission pathways, in the context of strengthening the global response to the threat of climate change, (pp. 3-26). World Meteorological Organization.

Lent, R. W., Lopez, A. M., Lopez, F. G., \& Sheu, H.-B. (2008). Social cognitive career theory and the prediction of interests and choice goals in the computing disciplines. Journal of Vocational Behavior, 73(1), 52-62. https://doi.org/10.1016/j.jvb.2008.01.002

Lent, R. W., Sheu, H. Bin, Miller, M. J., Cusick, M. E., Penn, L. T., \& Truong, N. N. (2018). Predictors of science, technology, engineering, and mathematics choice options: A metaanalytic path analysis of the social-cognitive choice model by gender and race/ethnicity. Journal of Counseling Psychology, 65(1), 17. https://doi.org/10.1037/cou0000243

Lindell, M. K., \& Perry, R. W. (2012). The protective action decision model: Theoretical modifications and additional evidence. Risk Analysis: An International Journal, 32(4), 616632. https://doi.org/10.1111/j.1539-6924.2011.01647.x

Makransky, G., Andreasen, N. K, Baceviciute S., \& Mayer R. M. (2020). Immersive virtual reality increases liking but not learning with a science simulation and generative learning strategies promote learning in immersive virtual reality. Journal of Educational Psychology. doi: 10.1037/edu0000473 
Makransky, G., Borre-Gude, S., \& Mayer, R. E. (2019a). Motivational and cognitive benefits of training in immersive virtual reality based on multiple assessments. Journal of Computer Assisted Learning, 35(6), 691-707. https://doi.org/10.1111/jcal.12375

Makransky, G., Wismer, P., \& Mayer, R. E. (2018). A gender matching effect in learning with pedagogical agents in an immersive virtual reality science simulation. Journal of Computer Assisted Learning, 35(5), 349-358. https://doi.org/10.1111/jcal.12335

Makransky, G., Bonde, M. T., Wulff, J. S. G., Wandall, J., Hood, M., Creed, P. A., Bache, I., Silahtaroglu, A., \& Nørremølle, A. (2016). Simulation based virtual learning environment in medical genetics counseling: An example of bridging the gap between theory and practice in medical education. BMC Medical Education, 16. https://doi.org/10.1186/s12909-016-0620-6

Makransky, G., \& Lilleholt, L. (2018). A structural equation modeling investigation of the emotional value of immersive virtual reality in education. Educational Technology Research and Development, 66(5), 1141-1164. https://doi.org/10.1007/s11423-018-9581-2

Makransky, G., \& Petersen, G. B. (2019). Investigating the process of learning with desktop virtual reality: A structural equation modeling approach. Computers \& Education, 134, 15-30. https://doi.org/10.1016/j.compedu.2019.02.002

Makransky, G., Terkildsen, T. S., \& Mayer, R. E. (2019b). Adding immersive virtual reality to a science lab simulation causes more presence but less learning. Learning and Instruction, 60, 225-236. https://doi.org/10.1016/j.learninstruc.2017.12.007

Makransky, G., Wandall, J., Madsen, S. R., Hood, M., \& Creed, P. (2019c). Development and validation of the UiL-Scales for measurement of development in life skills: A test battery of non-cognitive skills for danish school children. Scandinavian Journal of Educational Research, 1-16. https://doi.org/10.1080/00313831.2019.1595716

Markowitz, D. M., Laha, R., Perone, B. P., Pea, R. D., \& Bailenson, J. N. (2018). Immersive virtual 
reality field trips facilitate learning about climate change. Frontiers in Psychology, 9. https://doi.org/10.3389/fpsyg.2018.02364

Mayer, R. E. (2014). Introduction to multimedia learning. In R. E. Mayer (Ed.), The cambridge handbook of multimedia learning (pp. 1-24). Cambridge University Press.

Mayer, R. E., Mathias, A., \& Wetzell, K. (2002). Fostering understanding of multimedia messages through pre-training: Evidence for a two-stage theory of mental model construction. Journal of Experimental Psychology: Applied, 8(3), 147-154. https://doi.org/10.1037/1076-898X.8.3.147

Mayer, R. E., \& Pilegard, C. (2014). Principles for managing essential processing in multimedia learning: Segmenting, pre-training, and modality principles. In R. E. Mayer (Ed.), The cambridge handbook of multimedia learning ( $2^{\text {nd }}$ ed.) (pp. 316-344). Cambridge University Press.

Meyer, O. A., Omdahl, M. K., \& Makransky, G. (2019). Investigating the effect of pre-training when learning through immersive virtual reality and video: A media and methods experiment. Computers \& Education, 140. https://doi.org/10.1016/j.compedu.2019.103603

Mieg, H. A. (2019). Introduction: Inquiry-based learning - Initial assessment. In H. A. Mieg (Ed.), Inquiry-based learning: Undergraduate research: The German multidisciplinary experience (pp. 1-16). Springer International Publishing. https://doi.org/10.1007/978-3-030-14223-0_1

Moreno, R., \& Mayer, R. E. (2002). Learning science in virtual reality multimedia environments: Role of methods and media. Journal of Educational Psychology, 94(3), 598-610. https://doi.org/10.1037/0022-0663.94.3.598

Moreno, R., \& Mayer, R. (2007). Interactive multimodal learning environments. Educational Psychology Review, 19(3), 309-326. http://dx.doi.org/10.1007/s10648-007-9047-2

Parong, J., \& Mayer, R. (2018). Learning science in immersive virtual reality. Journal of Educational Psychology, 110, 785-797. https://doi.org/10.1037/edu0000241 
Pedaste, M., Mäeots, M., Siiman, L. A., de Jong, T., van Riesen, S. A. N., Kamp, E. T., Manoli, C. C., Zacharia, Z. C., \& Tsourlidaki, E. (2015). Phases of inquiry-based learning: Definitions and the inquiry cycle. Educational Research Review, 14, 47-61. https://doi.org/10.1016/j.edurev.2015.02.003

Pomplun, M., \& Sunkara, S. (2003). Pupil dilation as an indicator of cognitive workload in humancomputer interaction. Proceedings of the International Conference on HCI, 273.

Prawat, R. S. (1989). Promoting access to knowledge, strategy, and disposition in students: A research synthesis. Review of educational research, 59(1), 1-41. https://doi.org/10.3102/00346543059001001

Queiroz, A. C. M., Nascimento, A. M., Tori, R., \& da Silva Leme, M. I. (2018). Using HMD-based immersive virtual environments in primary/K-12 education. In D. Beck, C. Allison, L. Morgado, J. Pirker, A. Peña-Rios, T. Ogle, J. Richter, \& C. Gütl (Eds.), Immersive learning research network (pp. 160-173). Springer International Publishing.

Richardson, J. T. E. (2011). Eta squared and partial eta squared as measures of effect size in educational research. Educational Research Review, 6(2), 135-147. https://doi.org/10.1016/j.edurev.2010.12.001

Schreiner, C., Henriksen, E. K., \& Hansen, P. J. K. (2005). Climate education: Empowering today's youth to meet tomorrow's challenges. Studies in Science Education, 41(1), 3-49. https://doi.org/10.1080/03057260508560213

Schunk, D. H., \& DiBenedetto, M. K. (2016). Self-efficacy theory in education. In K. R. Wentzel \& D. B. Miele (Eds.), Handbook of motivation at school. Routledge. https://doi.org/10.4324/9781315773384.ch3

Schunk, D. H., \& Pajares, F. (2002). The development of academic self-efficacy. In A. Wigfield \& J. S. Eccles (Eds.), Development of achievement motivation (pp. 15-31). Elsevier. 
Stainfield, J., Fisher, P., Ford, B., \& Solem, M. (2000). International virtual field trips: A new direction? Journal of Geography in Higher Education, 24(2), 255-262. https://doi.org/10.1080/713677387

Stansbury, M. (2014). Ten of the best virtual field trips. Wabisabi Learning. https://www.wabisabilearning.com/blog/ten-of-the-best-virtual-field-trips

Tarr, B., Slater, M., \& Cohen, E. (2018). Synchrony and social connection in immersive virtual reality. Scientific Reports, 8(1), 1-8. https://doi.org/10.1038/s41598-018-21765-4

The Danish Ministry of Education. (2018). National science strategy. https://www.uvm.dk/publikationer/folkeskolen/2018-national-naturvidenskabsstrategi

Thisgaard, M., \& Makransky, G. (2017). Virtual learning simulations in high school: Effects on cognitive and non-cognitive outcomes and implications on the development of STEM academic and career choice. Frontiers in Psychology, 8. https://doi.org/10.3389/fpsyg.2017.00805

van Valkengoed, A. M., \& Steg, L. (2019). Meta-analyses of factors motivating climate change adaptation behaviour. Nature Climate Change, 9(2), 158-163. https://doi.org/10.1038/s41558$018-0371-y$

Varma, K., \& Linn, M. C. (2012). Using interactive technology to support students' understanding of the greenhouse effect and global warming. Journal of Science Education and Technology, 21, 453-464. https://doi.org/10.1007/s10956-011-9337-9

Wade, S. E. (1992). How interest affects learning from text. In K. A. Renninger, S. Hidi, \& A. Krapp (Eds.), The role of interest in learning and development (pp. 225-278). Erlbaum.

Witmer, B. G., \& Singer, M. J. (1998). Measuring presence in virtual environments: A presence questionnaire. Presence: Teleoperators and Virtual Environments, 7(3), 225-240. https://doi.org/10.1162/105474698565686 
Woerner, J. J. (1999). Virtual field trips in the earth science classroom.

Xin, B., Chen, G., Wang, Y., Bai, G., Gao, X., Chu, J., Xiao, J., \& Liu, T. (2019). The efficacy of immersive virtual reality surgical simulator training for pedicle screw placement: A randomized double-blind controlled trial. World Neurosurgery, 124, 324-330. https://doi.org/10.1016/j.wneu.2018.12.090

Zhang, L., Bowman, D. A., \& Jones, C. N. (2019). Exploring effects of interactivity on learning with interactive storytelling in immersive virtual reality. 2019 11th International Conference on Virtual Worlds and Games for Serious Applications, VS-Games 2019 - Proceedings. https://doi.org/10.1109/VS-Games.2019.8864531 


\section{Appendix A}

Survey items used in the pre- and post-assessment.

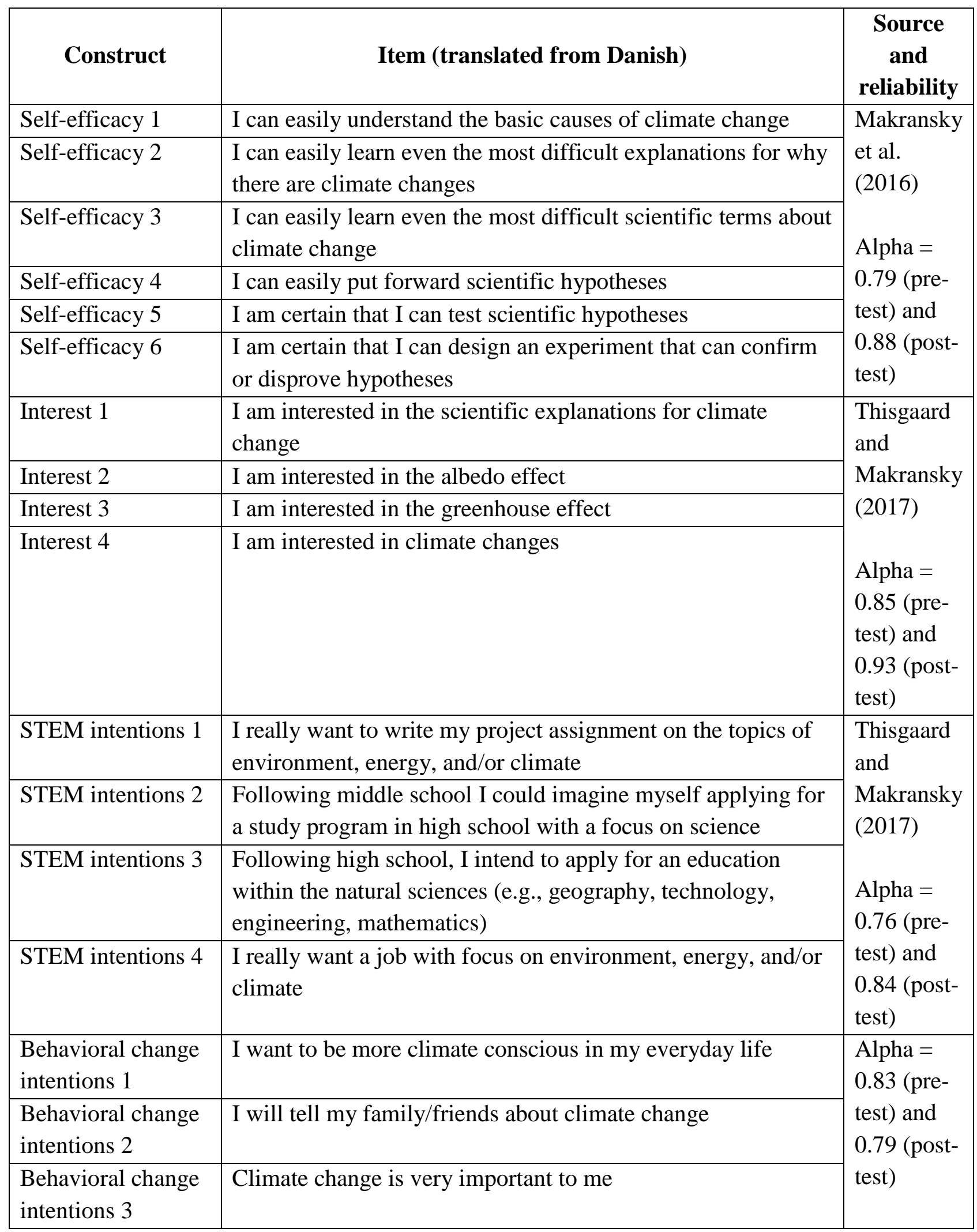




\begin{tabular}{|c|c|c|}
\hline $\begin{array}{l}\text { Outcome } \\
\text { expectations } 1\end{array}$ & $\begin{array}{l}\text { With an education in the area of environment, energy, and/or } \\
\text { climate, I can do good things for society and mankind }\end{array}$ & $\begin{array}{l}\text { Makransky } \\
\text { et al. }\end{array}$ \\
\hline $\begin{array}{l}\text { Outcome } \\
\text { expectations } 2\end{array}$ & $\begin{array}{l}\text { With a job in the area of environment, energy, and/or climate, } \\
\text { I get to work alongside interesting colleagues }\end{array}$ & $(2019 c)$ \\
\hline $\begin{array}{l}\text { Outcome } \\
\text { expectations } 3\end{array}$ & $\begin{array}{l}\text { With an education in the area of science, I can achieve high } \\
\text { status }\end{array}$ & $\begin{array}{l}\text { Alpha = } \\
0.73 \text { (pre- } \\
\text { test) and } \\
0.79 \text { (post- } \\
\text { test) }\end{array}$ \\
\hline
\end{tabular}

Test items used in the pre- and post-assessment of knowledge.

\begin{tabular}{|c|c|c|}
\hline Construct & Item (translated from Danish) & Reliability \\
\hline Learning 1 & $\begin{array}{l}\text { How much ice is melting in Greenland yearly compared to } \\
\text { previously? a) Twice as much, b) Three times as much, c) } \\
\text { Four times as much, d) Five times as much }\end{array}$ & \multirow[t]{6}{*}{$\begin{array}{l}\text { Alpha }= \\
0.70 \text { (post- } \\
\text { test) }\end{array}$} \\
\hline Learning 2 & $\begin{array}{l}\text { What is meant by the greenhouse effect? a) An isolating layer } \\
\text { of gasses around the Earth, which keeps in the heat, b) Air } \\
\text { pollution from factories and cars, which creates a "duvet" } \\
\text { over many cities, c) An isolating layer of gasses around the } \\
\text { Earth, which keeps Earth cool, d) When a hole is made in the } \\
\text { ozone layer and Earth's oxygen is released into the } \\
\text { atmosphere }\end{array}$ & \\
\hline Learning 3 & $\begin{array}{l}\text { Which gas, which contributes to an increase in the greenhouse } \\
\text { effect, has been released into the atmosphere in large } \\
\text { quantities during the last few years? a) Oxygen, b) Carbon } \\
\text { monoxide, c) Carbon dioxide }\end{array}$ & \\
\hline Learning 4 & $\begin{array}{l}\text { When did the manmade augmentation of the greenhouse } \\
\text { effect really spark off? a) During the industrial revolution in } \\
\text { the 19th century, b) During the oil crisis in the 1970's, c) } \\
\text { During the Second World War in the 1940's, d) During the } \\
\text { climate crisis in the 1990's }\end{array}$ & \\
\hline Learning 5 & $\begin{array}{l}\text { The biggest human contribution to the greenhouse effect } \\
\text { stems from a) Plastic in the oceans, b) Fossil fuels, c) Nuclear } \\
\text { power, d) Solar and wind energy }\end{array}$ & \\
\hline Learning 6 & $\begin{array}{l}\text { What has been experimented with in order to counteract the } \\
\text { acidification of the oceans around Greenland? a) Banning the } \\
\text { discharge of meltwater, b) Removing plastic and other } \\
\text { polluters from the oceans, c) Establishing forests of seaweed, } \\
\text { d) Adding a basic material to the ocean }\end{array}$ & \\
\hline
\end{tabular}




\begin{tabular}{|c|c|}
\hline Learning 7 & $\begin{array}{l}\text { What is true and false about albedo? a) Albedo is a layer of } \\
\text { gasses that regulate Earth's temperature, b) Albedo is a } \\
\text { measure of the radiation that is reflected back into space, c) } \\
\text { Albedo is also the name of an international agreement } \\
\text { concerning global warming, d) Albedo is a measure of the } \\
\text { radiation that is absorbed when sun hits the surface of the } \\
\text { Earth, e) O2, CO2, NO2, and CNO2 have high albedos, f) } \\
\text { Seawater and land have high albedos, f) Snow and ice have } \\
\text { high albedos, g) Albedo is a greenhouse gas }\end{array}$ \\
\hline Learning 8 & $\begin{array}{l}\text { What happens to the planet when the ice and snow in } \\
\text { Greenland melt? a) The planet is warmed via ice-albedo } \\
\text { feedback, b) The temperature decreases because the ice and } \\
\text { snow release cooling gasses, c) The temperature decreases } \\
\text { because the oceans are cooled, d) The air temperature } \\
\text { increases because there is less snow and ice, e) It leads to a } \\
\text { higher concentration of corals, f) It leads to an increased } \\
\text { reflection of energy, which cools the planet via ice-albedo } \\
\text { feedback }\end{array}$ \\
\hline Learning 9 & $\begin{array}{l}\text { What happens if soot is covering ice and snow? a) The soot } \\
\text { isolates and prevents the ice and snow from melting, b) The } \\
\text { soot is gradually dissolved and nothing else happens, c) The } \\
\text { soot is cooled and releases greenhouse gasses, d) The soot } \\
\text { absorbs the radiation of the sun resulting in the snow and ice } \\
\text { melting }\end{array}$ \\
\hline Learning 10 & $\begin{array}{l}\text { What connection is there between the greenhouse effect and } \\
\text { the melting of ice? a) There is no connection, b) When water } \\
\text { goes from solid to liquid form, CO2 is released, c) When ice } \\
\text { melts, sea temperatures increase - this makes plastic in the } \\
\text { oceans release greenhouse gasses, d) When water goes from } \\
\text { solid to liquid form, CO2 is absorbed }\end{array}$ \\
\hline Learning 11 & $\begin{array}{l}\text { How many people is expected to require evacuation during } \\
\text { this century as a consequence of rising sea levels produced by } \\
\text { melting ice? a) Between } 10 \text { million and a } 100 \text { million, b) } \\
\text { Approximately } 5 \text { million, c) Approximately } 500.000 \text {, d) Less } \\
\text { than } 100.000\end{array}$ \\
\hline
\end{tabular}




\section{Appendix B}

List of questions in the exercise sheet.

1) What did you see on Greenland? (observation)

2) What do you already know about climate that is relevant for the journey to Greenland? (research)

3) What surprises you about what you saw on Greenland? (question)

4) Why do you think it looked the way it did on Greenland? Use theory and concepts in your explanation (hypothesis)

5) If you are right, how will it progress? (prediction)

6) How can you test if you are right? Explain or draw how it can be tested - how should one proceed? (experiment design) 